\title{
PRODUKTIVITAS PENANGKAPAN IKAN TONGKOL (Euthynnus affinis) MENGGUNAKAN PURSE SEINE DI PERAIRAN BONTOBAHARI KABUPATEN BULUKUMBA DAN HUBUNGANNYA DENGAN KONDISI OSEANOGRAFI
}

\author{
THE RELATIONSHIP BETWEEN PRODUCTIVITY OF COB (EuthynnuS \\ affinis) FISHING USING PUERSE SEINE IN BONTOBAHARI WATERS OF \\ BULUKUMBA REGENCY AND ITS RELATIONSHIP WITH OCEANOGRAPHIC
}

\author{
Nuraisyah Nuraisyah $^{1 *}$, Alfa F.P Nelwan ${ }^{1}$, St Aisjah Farhum ${ }^{1}$ \\ ${ }^{1}$ Program Studi Pemanfaatan Sumberdaya Perikanan Fakultas Ilmu Kelautan \\ dan Periknan Universitas Hasanuddin \\ *nuraisyahputri89@yahoo.com
}

Diterima: 9 Juni 2019; Disetujui: 28 Agustus 2019

\begin{abstract}
ABSTRAK
Penelitian ini bertujuan untuk menghitung produktivitas hasil tangkapan dan hubungannya dengan kondisi oseanografi. Penelitian ini dilaksanakan pada bulan Mei-Juli 2018 yang bertempat di Desa Tana Beru, Kecamatan Bontobahari, Kabupaten Bulukumba. Metode penelitian yang digunakan adalah metode studi kasus, pengambilan data dilakukan dengan mengikuti operasi penangkapan selama 30 trip. Meliputi pengukuran dan penimbangan hasil tangkapan, perhitungan waktu penarikan tali kolor dan parameter oseanografi. Analisis data dilakukan terhadap produktivitas hasil tangkapan ikan tongkol (Euthynnus affinis) dan hubungan produktivitas hasil tangkapan dengan kondisi oseanografi menggunakan uji cobb douglas. Hasil penelitian menunjukkan ikan tongkol yang tertangkap dengan purse seine hidup pada kisaran suhu 27$30^{\circ} \mathrm{C}$. Produktivitas penangkapan ikan tongkol dengan purse seine berkisaran antara $1.87 \mathrm{~kg} / \mathrm{menit}-14.50$ $\mathrm{kg} /$ menit, dan berdasalkan analisis regresi diketahui bahwa suhu memiliki hubungan yang signifikan terhadap produktivitas penangkapan.
\end{abstract}

Kata kunci: Produktivitas, Euthynnus affinis, suhu, salinitas

\begin{abstract}
This study aimed to calculate catch productivity and its relationship with oceanographic conditions. This research was conducted in May-July 2018 in Tana Beru Village, Bontobahari District, Bulukumba Regency. The research method used was a case study method, data collection was carried out by following fishing operations for 30 trips. Includes measurement and weighing of catches, calculation of draw string draw time and oceanographic parameters. Data analysis was performed on productivity of tuna catches (Euthynnus affinis) and the relationship of productivity of catches with oceanographic conditions using the Douglas Cobb test. The results showed that tuna caught with purse seine lived in a temperature range of $27-30^{\circ} \mathrm{C}$. Productivity of tuna fishing with purse seine ranged from $1.87 \mathrm{~kg} /$ minute $-14.50 \mathrm{~kg} /$ minute, and based on regression analysis it was found that temperature had a significant relationship to productivity of capture.
\end{abstract}

Keywords: Productivity, Euthynnus affinis, temperature, salinity 


\section{PENDAHULUAN}

Kabupaten Bulukumba merupakan salah satu daerah di Sulawesi Selatan yang potensi perikanannya cukup tinggi. Terletak di bagian selatan Jasirah Sulawesi dan berjarak kurang lebih $153 \mathrm{~km}$ dari ibu kota provinsi Sulawesi Selatan dengan letak geografis $5^{0} 20^{\prime \prime} 5^{\circ} 40^{\prime \prime}$ Lintang Selatan dan $119^{0} 50^{\prime \prime} 120^{\circ} 28^{\prime \prime}$ Bujur Timur. Ditinjau dari segi geografis Kabupaten Bulukumba adalah salah satu Kabupaten yang sangat potensial dari aspek kelautan dan perikanan dengan luas wilayah $1.154,67 \mathrm{~km}^{2}$ dan panjang pantai sekitar $128 \mathrm{~km}$ dengan produksi perikanan tangkap sebesar 53.612,3 ton. Jumlah unit alat tangkap purse seine Kabupaten Bulukumba sebanyak 150 unit (Statistik Perikanan Bulukumba, 2014).

Salah satu produksi terbesar di Kabupaten Bulukumba adalah Ikan Tongkol (Euthynnus affinis) yang merupakan salah satu sumberdaya perikanan laut yang dikategorikan sebagai ikan pelagis, dimana hasil tangkapan ikan tongkol bervariasi di setiap tahunnya, Produksi ikan tongkol pada tahun 2014 sebesar 14.102 ton (Statistik Perikanan Bulukumba, 2014).

Purse seine atau pukat cincin merupakan alat tangkap yang efektif untuk menangkap ikan pelagis yang memiliki tingkah laku hidup berkelompok dalam ukuran besar, baik di daerah perairan pantai maupun lepas pantai. Prinsip menangkap ikan dengan purse seine yaitu melingkari gerombolan ikan dengan jaring, sehingga jaring tersebut membentuk dinding vertikal, dengan demikian gerakan ikan ke arah horizontal dapat dihalangi. Setelah itu bagian bawah jaring dikerucutkan untuk mencegah ikan lari ke arah bawah jaring (Permana, 2010).

Jenis-jenis ikan yang menjadi tangkapan utama dari alat tangkap purse seine adalah jenis ikan pelagis. Ikan yang menjadi tangkapan purse seine adalah Layang (Decapterus sp), lemuru (Sardinela sp), kembung (Rastreliger $s p$ ), tongkol (E. affinis), dan cakalang (katsuwonus pelamis) (Permana, 2010).

Ikan tongkol (E. affinis) salah satu jenis dari kelompok ikan pelagis, dengan penyebaran meliputi seluruh daerah pantai dan lepas pantai perairan indonesia, serta seluruh perairan Indo-pasifik. Spesies ini hidup dalam bergerombol, dan mempunyai kebiasaan hidup berpindah tempat karena keinginan untuk mencari daerah yang cocok, kaya akan makanan, ataupun karena adanya perubahan suhu yang mencolok (Girsang., 2008). 
Distribusi Ikan Tongkol ( $E$. affinis) sangat ditentukan oleh berbagai faktor, baik faktor internal ikan itu sendiri maupun faktor eksternal dari lingkungan. Faktor internal meliputi jenis (genetis), umur dan ukuran, serta tingkah laku (behavior). Faktor eksternal merupakan faktor lingkungan, diantaranya adalah parameter oseonografi seperti suhu dan salinitas (Girsang HS. 2008).

Mengingat besarnya potensi ikan-ikan pelagis di Kabupaten Bulukumba maka perlu adanya perhatian yang baik terhadap jenis ikan tersebut, terutama pada jenis ikan tongkol serta kemampuan suatu alat tangkap dalam memperolehhasil tangkapan. Dari uraian tersebut maka perlu dilakukan penelitian untuk mengetahui “Produktivitas Penangkapan Ikan Tongkol ( $E$. affinis) menggunakan Purse Seine di Perairan Bontobahari Kabupaten Bulukumba dan Hubungannya Dengan Kondis: -.-- og ografi.

$$
\text { Adapun Tujuan per adalah }
$$

menghitung produktivitas penangkapan Ikan tongkol ( $E$. affinis) dan menentukan hubungan antara produktivitas hasil tangkapan dengan kondisi oseanografi.

\section{BAHAN DAN METODE}

\section{Waktu dan Tempat}

Penelitian ini dilaksanakan pada bulan Mei - Juli 2018. Perolehan data hasil tangkapan dan parameter oseanografi dilakukan di wilayah Bontobahari dengan fishing base di Desa Tanah Beru Kabupaten Bulukumba.

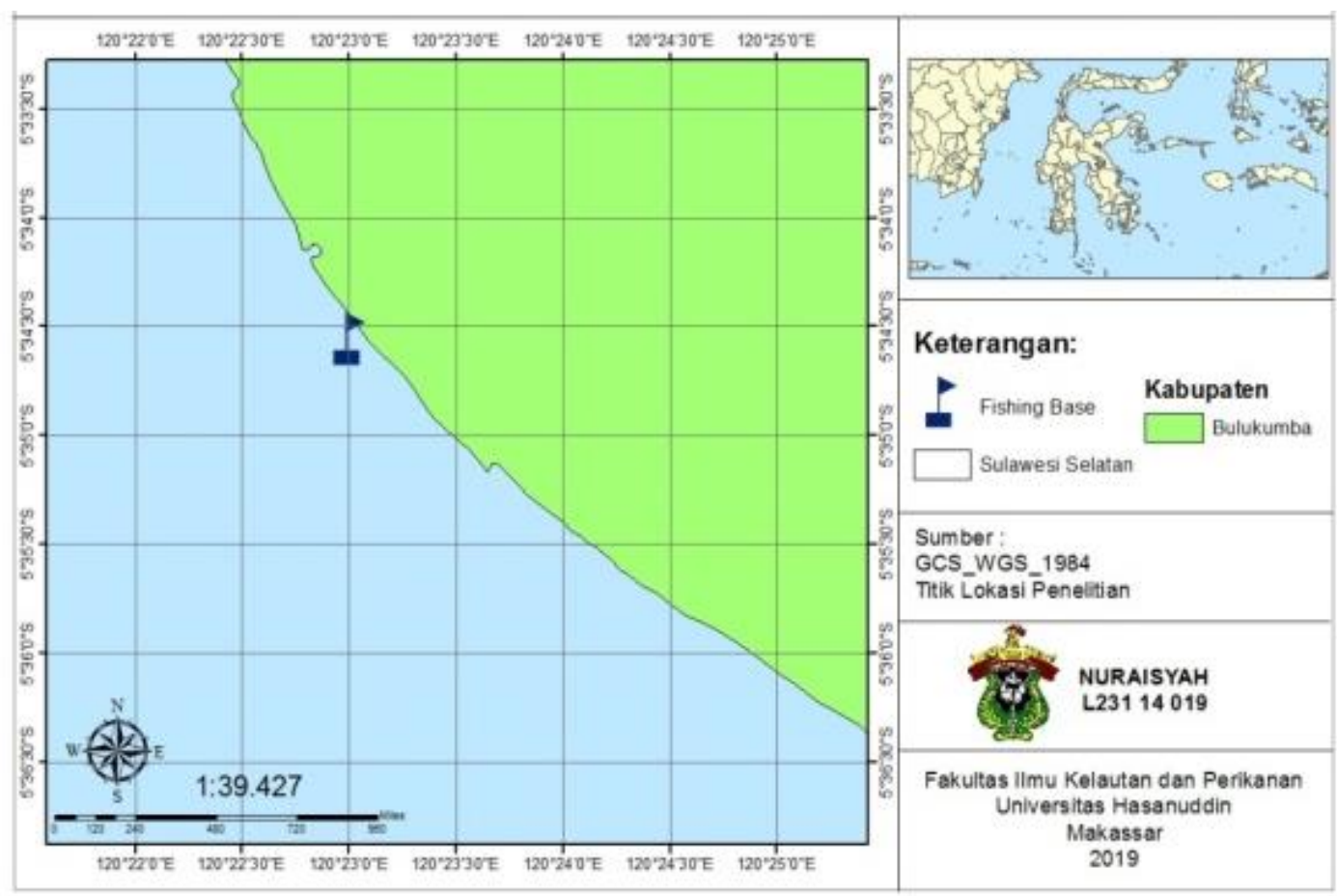

Gambar 1. Lokasi fishing base di Desa Tanah Beru Kabupaten Bulukumba 


\section{Metode Penelitian}

Penelitian ini dilakukan dengan menggunakan metode studi kasus pada satu unit purse seine. Data yang dikumpulkan adalah data primer dan sekunder. Data primer diperoleh melalui observasi langsung dengan mengikuti operasi penangkapan purse seine diperairan Bontobahari Kabupaten Bulukumba sebanyak 30 trip. Jenis data primer yang dikumpulkan yaitu :

1. Durasi lama penangkapan diperoleh dengan cara menghitung waktu (menit) yang dihitung mulai proses pelingkaran jaring diturunkan sampai seluruh cincin/pemberat sudah didek kapal.

2. Mengambil data kondisi oseanografi suhu dan salinitas dilakukan dengan menggunakan refractometer dan

Thermometer. Data oseanografi diambil dua kali yakni pada saat setting dan setelah hauling.

3. Berat ikan tongkol dangan cara, mengukur panjang ikan dengan mengambil 3 sampel ikan tongkol yang kemudian di timbang.

4. Posisi geografis penangkapan dilakukan setiap kali hauling.

Data sekunder diperoleh dengan melakukan wawancara langsung dengan nelayan yang berkaitan dengan spesifikasi alat tangkap serta jenis ikan yang tertangkap dan menggunakan buku serta jurnal sebagai data tambahan.

\section{Analisis Data}

\section{Menghitung Produktivitas Hasil Tangkapan Purse Seine}

Pada tahap ini dilakukan perhitungan produktivitas hasil tangkapan purse seine. Perhitungan produktivitas purse seine menggunakan persamaan sebagai berikut :

$$
\text { Produktivitas }=\frac{c}{t}
$$

Dimana:

Prd = Produktivitas purse seine $(\mathrm{kg})$

$\mathrm{C}=$ Total jumlah hasil tangkapan pertrip $(\mathrm{kg})$

$\mathrm{t}=$ Actual fishing time (menit) Dihitung mulai dari proses pelingkaran sampai seluruh pemberat sudah dinaikkan didek kapal.

\section{Hubungan Produktivitas Hasil Tangkapan dengan kondisi Oseanografi}

Untuk mengetahui hubungan antara produktivitas dengan kondisi oseanografi digunakan analisis statistik regresi Cobb Dounglas.

Formulasi dari analisis cobb douglas tersebut sebagai berikut :

$$
\widehat{y}=a x 1^{b 1} \cdot x 2^{b 2} \ldots \ldots \ldots \ldots \ldots n x^{b n} \cdot e
$$

Untuk mengetahui hubungan parameter oseanografi dan produktivitas juga digunakan regresi Cobb Douglas. Farmulasi dari analisis tersebut sebegai berikut :

$$
(\widehat{y})=a+b_{1} \log x_{1}+b_{2} \log x_{2}
$$




\section{Dimana :}

$\hat{y}=$ Berat total hasil tangkapan $(\mathrm{kg})$

$a=$ koefisien potongan (konstanta)

$b_{1}=$ Koefisien regresi parameter suhu

$b_{2}=$ koefisien regresi parameter salinitas

$x_{1}=\operatorname{Suhu}(\mathrm{C})$

$x_{2}=$ Salinitas $(\mathrm{ph})$

Sebelum melakukan analisis regresi data yang diperoleh harus dinormalkan terlebih dahulu menggunakan beberapa uji asumsi klasik. Ada beberapa tahap yang perlu dilakukan yakni :

\section{a. Uji Normalitas}

Uji normalitas data digunakan sebagai uji analisis untuk menyeleksi data apakah terdistribusi normal atau tidak normal dengan menggunakan uji kolmogorov- smirnov. Uji kolmogorov-smirnov merupakan pengujian normalitas yang banyak digunakan. Kelebihan dari uji ini adalah sederhana dan tidak menimbulkan perbedaan persepsi diatara satu pengamat dengan pengamat yang lain..

Hipotesis yang digunakan dalam uji normalitas adalah sebagai berikut :

$\mathrm{H}_{\circ}$ : Hasi tangkapan normal

$\mathrm{H}_{\mathrm{i}}$ : Hasi tangkapan tidak normal

Pengambilan keputusan

- Jika nilai significantlebih > dari 0.05 maka dikatakan normal

- Jika nilai significantlebih < dari 0.05 maka dikatakan tidak normal

\section{b. Uji Multikolinieritas}

Pengujian ini digunakan sebagai uji analisis untuk melihat ada tidakyna multikolineritas pada regresi yaitu dengan melihat nilai Tolerance dan VIF. Dasar pengambilan keputusan pada Uji Multikolonieritas dapat dilakukan dengan dua cara yaitu:

Melihat nilai Tolerance:

a. Jika nilai Tolerance lebih $>$ dari 0,10 maka artinya tidak terjadi Multikolineritas terhadap data yang di uji

b. Jika nilai Tolerance lebih $<$ dari 0,10 maka artinya terjadi Multikolineritas terhadap data yang di uji

\section{Analisis Stepwise}

Analisis stepwise digunakan sebagai analisis untuk menyeleksi data yang significantpada tahap uji multikolineritas, dimana analisis stepwise akan mengeluarkan secara otomoatis data $\mathrm{X}$ yang tidak significant sehingga menunjukan apakah data merupakan regresi sederhana ataupun regresi berganda.

\section{c. Uji Autokorelasi}

Autokorelasi digunakan untuk menguji suatu model regresi, apakah terdapat autokorelasi antara variabel dependen dengan independen. 
Untuk mengetahui keberadaan autokorelasi, kita dapat menggunakan metode Durbin Watson (DW). dengan ketentuan sebagai berikut:

$\mathrm{H}_{\circ} \quad=$ tidak ada autokorelasi.

$\mathrm{H}_{1} \quad=$ ada autokorelasi.

Dasar pengambilan keputusan

1). Bila nilai $d w$ di bawah signifikan (-2) berarti diindikasi tidak ada autokorelasi

2). Bila nilai dw di atas signifikan (2) berarti diindikasi ada autokorelasi

2). Bila nilai dw di antara (-2) sampai (2) berarti diindikasi tidak dapat disimpulkan

\section{HASIL DAN PEMBAHASAN}

\section{Gambaran Umum Lokasi Penelitian}

Kecamatan Bontobahari merupakan wilayah dataran yang memiliki wilayah seluas 108,6 km². Kecamatan Bontobahari didominasi oleh batuan karang yang mimilki tipe slope dengan tingkat kecerahan sangat baik dan memilki perairan dalam sehingga potensi perikanannya cukup besar. Desa Tanah Beru terletak di Kabupaten Bulukumba (Gambar 2) merupakan kawasan dengan potensi sumberdaya alam yang melimpah terkhusus pada potensi perikanan dengan kedalaman perairan \pm 30 meter.

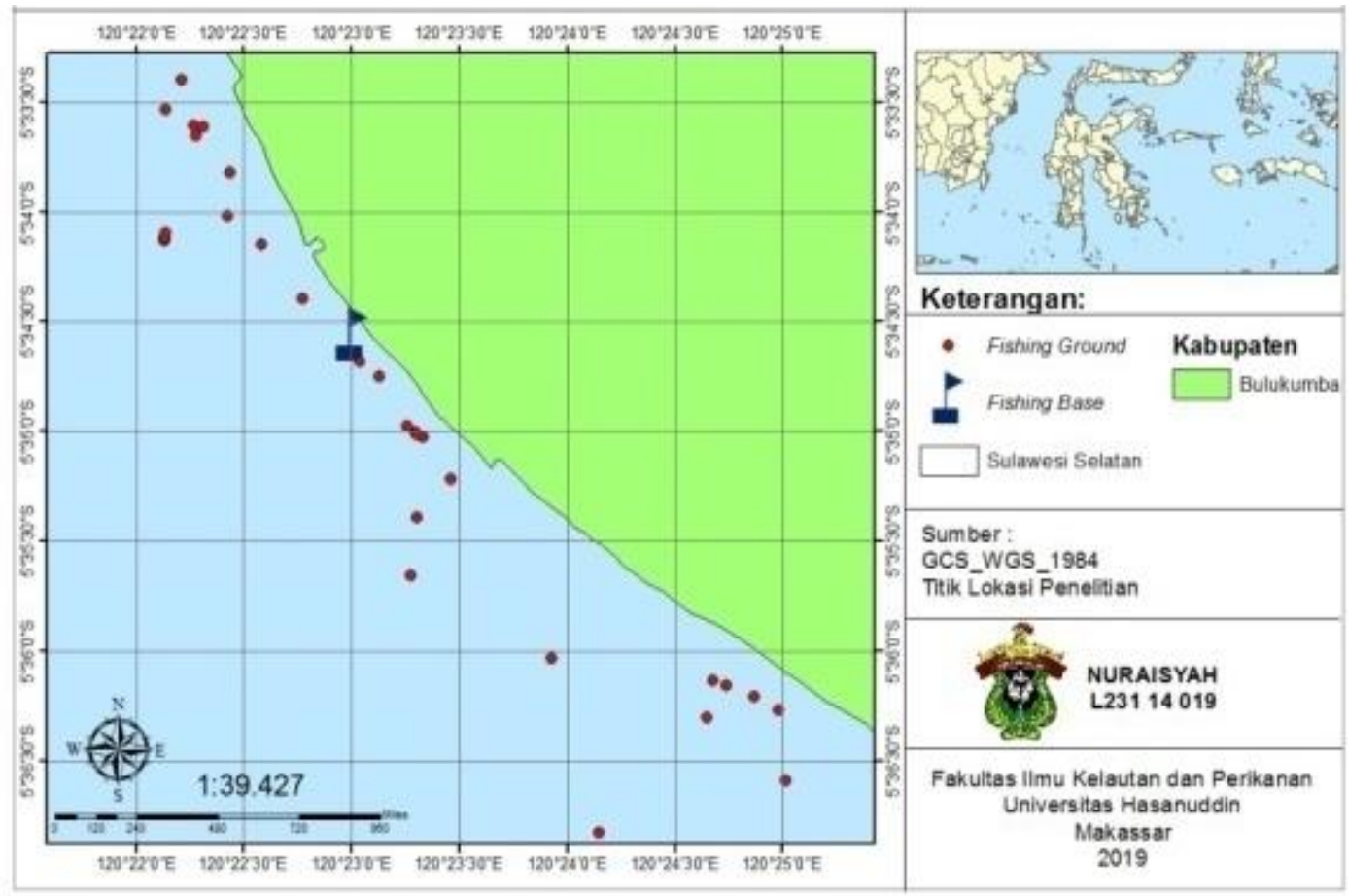

Gambar 2. Daerah penangkapan purse seine di Perairan Bontobahari Kabupaten Bulukumba

\section{Produktivitas Hasil Tangkapan Purse Seine}

Diagram produktivitas penangkapan purse seine dapat dideskripsikan sebagai mana dapat dilihat (Gambar 18). 


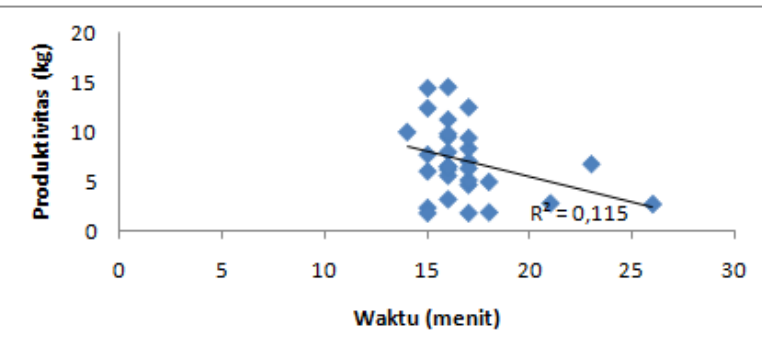

Gambar 3. Produktivitas penangkapan ikan tongkol pada purse seine

Produktivitas

penangkapan

merupakan kemampuan suatu alat tangkap untuk mendapatkan sejumlah hasil tangkapan (sumberdaya ikan yang menjadi tujuan penangkapan) dalam setiap satuan upaya penangkapan. Produktivitas purse seine dihitung berdasarkan perbandingan jumlah hasil tangkapan berdasarkan waktu yang dibutuhkan dalam proses penangkapan. Waktu yang diperoleh pada produktivitas hasil tangkapan purse seine yaitu pada saat proses pelingkaran jaring diturunkan sampai seluruh cincin/pemberat sudah didek kapal.

Berdasarkan jumlah produksi purse seine selama 30 trip penangkapan dalam varian waktu yang berbeda dengan jumlah produktivitas penangkapan yang berbeda pula diperoleh dengan menggunakan grafik scatter pada grafik (Gambar 3) dengan kisaran waktu yang dibutuhkan yaitu 15,16 25 menit dengan produksi tertinggi dan terbanyak yaitu $14,50 \mathrm{Kg} /$ menit dengan perolehan waktu 16 menit dan produktivitas terendah yaitu 1,87 dengan perolehan waktu
26 menit. Diagram produktivitas menjelaskan bahwa semakin lama waktu yang diperoleh maka semakin kecil pula jumlah hasil tangkapan.Produktivitas purse seine yang dioperasikan nelayan sangat berpariasi bahkan menunjukkan trend produksi yang menurun dengan melihat garis linear produktivitas penangkapan yang hanya memiliki koofisien determinasi $\left(R^{2}\right)=0,115$ menunjukan bahwa pengaruh waktu efektif penangkapan terhadap produktivitas penangkapan sebesar $0,115 \%$ sisanya dipengaruhi oleh faktor lain. Upaya penangkapan yang dimaksud pada penelitian berkaitan teknis penangkapan yang meliputi : waktu pelingkaran jaring, kekuatan mesin roller dalam menarik tali pemberat, dan kekuatan jaring (Azlhimsyah,2016).

Setelah melakukan analisis dengan produktivita menunggunakan grafik scetterdi ketahui bahwa pengaruh produktivitas hasil tangkapan purse seine yaitu hanya sekitar 0,115\%, dikarenakan pada pengoperasian alat tangkap diperairan Bontobahari lokasi pengoperasian yang tidak sesuai dikarenakan lokasi penangkapan berada di daerah yang berkarang sehingga ada kemungkinan jaring dapat tersangkut pada batuan karang, kekuatan $A B K$ dalam pengoperasian alat tangkap dan ketersediaan ikan yang menjadi 
target tangkapan hal ini sesuai literatur (Azlhimsyah, 2016).

Selain faktor waktu penangkapan nilai produktivitas penangkapan dipengaruhi oleh beberapa faktor lain, dimana salah satunya yaitu kondisi oseanografi, ketersediaan makanan diperairan dan ukuran ikan yang berhasil ditangkap (Azlhimsyah, 2016).Tetapi penelitian yang dilakukan tidak meneliti tentang ketersediaan makanan, sebagai perbandingan produktivitas penangkapan purse seine dengan menggunakan alat bantu rumpon, pengaruh waktu yang diperoleh dalam produktivitas penangkapan lebih tinggi yaitu sebesar 0,1201\% dalam waktu yang berbeda beda disetiap pengoprasian (Idrus, 2016).

\section{Analisis Hubungan Produktivitas Hasil tangkapan dengan Kondisi Oseanografi}

Untuk mendapatkan hubungan produktivitas hasil tangkapan dengan kondisi oseanografi dilakukan analisis regresi sederhana Cobb Douglass. Produktivitas hasil tangkapan (y) dijadikan variabel bebas (independent) sedangkan oseanografi (X) dijadikan variabel tidak bebas (dependent).

$$
\mathrm{Y}=\mathrm{a} \cdot \mathrm{bX} 1+.
$$

Sebelum melakukan analisis Cobb Douglass dilakukan tahapan uji asumsi klasik yaitu :

\section{Hasil Uji Normalitas}

Berdasarkan hasil pengukuran parameter oseanografi Suhu (X1), Slinitas (X2) sebagai variabel bebas (independent) dan Produktivitas hasil tangkapan variabel tidak bebas (dependent). Produktivitas hasil tangkapan memiliki hub terhadap kondisi oseanografi dima... murat dilihat pada Tabel 1.

Tabel 1. Hasil uji normalitas Kolmogorov-Smirnov

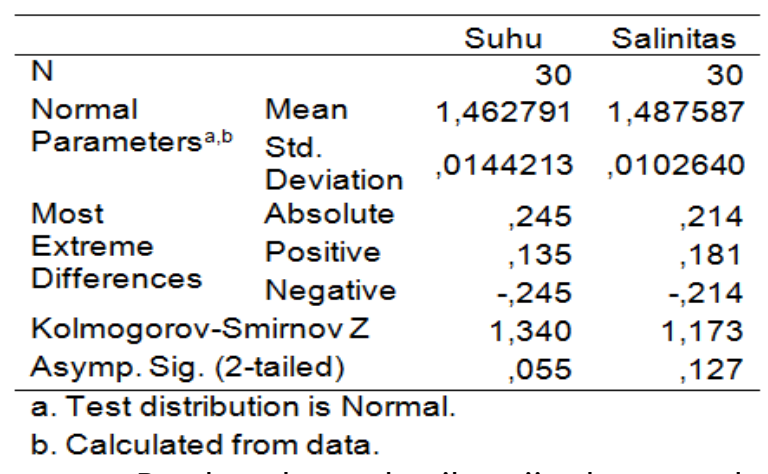

Berdasarkan hasil uji kenormalan residu produktivitas dan kondisi oseanografi dapat dilihat pada Tabel 3 Hasil uji normalitas dijelaskan bahwa nilai significant pada suhu adalah 0.055, salinitas 0.127 Dengan melihat asumsi apabila nilai > 0,05 maka dikatakan normal. Dimana diketahui bahwa sebaran data diatas dengan mengikuti asumsi bahwa nilai p-value lebih besar dari 0.05. sig. suhu > 0.05 yaitu 0.055 sig. Salinitas > 0.05 yaitu 0.127 dengan demikian hasil data tersebut terdistribusi normal $\left(\mathrm{H}_{\circ}\right)$.

\section{Hasil Uji Multikolineritas}


Uji Multikolineritas dapat disimpulkan bahwa tidak terdapat multikolineritas yang dapat dilihat pada Tabel 2.

Tabel 2. Uji Multikolineritas

\begin{tabular}{|c|c|c|c|c|c|c|c|c|c|c|c|c|}
\hline \multirow[b]{2}{*}{ Model } & \multicolumn{2}{|c|}{$\begin{array}{l}\text { Unstandardized } \\
\text { Coefficients }\end{array}$} & \multirow{2}{*}{$\begin{array}{c}\begin{array}{c}\text { Standar } \\
\text { dized }\end{array} \\
\text { Coeffici } \\
\text { ents } \\
\text { Beta }\end{array}$} & \multirow[b]{2}{*}{$t$} & \multirow[b]{2}{*}{ Sig. } & \multicolumn{2}{|c|}{$\begin{array}{l}95.0 \% \text { Confidence } \\
\text { Interval for } B\end{array}$} & \multicolumn{3}{|c|}{ Correlations } & \multicolumn{2}{|c|}{$\begin{array}{l}\text { Collinearity } \\
\text { Statistics }\end{array}$} \\
\hline & B & Std. Error & & & & $\begin{array}{l}\text { Lower } \\
\text { Bound }\end{array}$ & $\begin{array}{l}\text { Upper } \\
\text { Bound }\end{array}$ & $\begin{array}{l}\text { Zero- } \\
\text { order }\end{array}$ & Partial & Part & Tolerance & VIF \\
\hline (Constant) & $-397,532$ & 58,829 & & $-6,757$ &, 000 & $-518,038$ & $-277,027$ & & & & & \\
\hline Suhu & 277,273 & 40,215 &, 793 & 6,895 &, 000 & 194,896 & 359,650 & .793 & 793 & .793 & 1,000 & $1,00 C$ \\
\hline
\end{tabular}

a. Dependent Variable: Produktivitas

Tabel 2 menggunakan regresi Stepwise, uji regresi Stepwise bertujuan untuk menguji nilai variabel yang significant dan apabila terdapat variabel yang tidak significant maka variabel tersebut akan dikeluarkan, seperti pada tabel 2 . menjelaskan bahwa nilai VIF suhu kurang dari 10 pada tabel 2. Yaitu 1.000 dan nilai tolerance lebih dari 0.01 yaitu sebesar 1.000 sehingga dapat disimpulkan bahwa tidak terdapat Multikoloneritas. Pada analisis diatas digunakan regresi sederha dengan menggunakan model regresi Stepwise dimana hanya menggunakan satu variabel $(x)$ yaitu suhu. Sehingga dapat disimpulkan setelah melakukan uji stepwise bahwa tidak terdapat multikolineritas karena niali VIF $<10$ dan nilai Tolerance $>0,01$.

\section{Hasil Uji Autokorelasi}

Nilai DW (Durbin Watson) pada Tabel 3 menunjukkan bahwa tidak ada masalah autokorelasi

Tabel 3. Uji Autokorelasi

\begin{tabular}{|c|c|c|c|c|c|c|c|c|c|c|}
\hline \multirow[b]{2}{*}{ Model } & \multirow[b]{2}{*}{$\mathrm{R}$} & \multirow[b]{2}{*}{$\begin{array}{l}\mathrm{R} \\
\text { Squ } \\
\text { are }\end{array}$} & \multirow[b]{2}{*}{$\begin{array}{c}\text { Adjusted } \\
\text { R } \\
\text { Square }\end{array}$} & \multirow[b]{2}{*}{$\begin{array}{l}\text { Std. Error } \\
\text { of the } \\
\text { Estimate }\end{array}$} & \multicolumn{5}{|c|}{ Change Statistics } & \multirow[b]{2}{*}{$\begin{array}{l}\text { Durbin- } \\
\text { Watson }\end{array}$} \\
\hline & & & & & $\begin{array}{c}R \\
\text { Square } \\
\text { Change }\end{array}$ & $\begin{array}{c}F \\
\text { Change }\end{array}$ & df1 & df2 & $\begin{array}{l}\text { Sig. F } \\
\text { Change }\end{array}$ & \\
\hline 1 & $.815^{a}$ & ,665 & 640 & 3,0246329 & 665 & 26,769 & 2 & 27 &, 000 & 1,946 \\
\hline
\end{tabular}

Nilai hasil pengujian Durbin Watson dapat dilihat pada Tabel 3 menjelaskan bahwa nilai Durbin watson yang didapatkan setelah pengujian yaitu 1.946 menunjukkan tidak adanya masalah autokorelasi dari parameter yang diamati dimana jika nilai DW -2 maka tidak ada masalah autokorelasi, sedangkan +2 berarti terdapat autokorelasi dengan jumlah data (n) sebanyak 30 dan jumlah data variabel sebanyak 2 (suhu dan 
salinitas). Dengan demikian dapat diketahui bahwa sebaran data diatas tidak terjadi autokorelasi $\left(\mathrm{H}_{0}\right)<2$ yaitu 1.946 .

Berdasarkan hasil analisis regresi sederhana, diketahui variabel suhu yang bernilai significant sehingga didapatkan persamaan model sebagai berikut:

$$
Y=-397,532+277,273 x_{I}
$$

Koefisien suhu $\left(\mathrm{x}_{\mathrm{I}}\right)$ yang bernilai positif yakni 277,273. Hal ini menjelaskan bahwa setiap kenaikan $\quad 1^{\circ} \mathrm{C}$ maka produktivitas penangkapan akan bertambah juga sebesar $277,273 \mathrm{~kg} / \mathrm{m}^{3}$ menit pada variabel $\left(\mathrm{x}_{\mathrm{I}}\right)$. hal ini menunjukkan bahwa hubungan produktivitas dengan kondisi oseanografi memiliki keterkaitan krn nilai $\left(\mathrm{x}_{\mathrm{I}}\right)$ yang diapatkan $>1$.

diatas dapat dilihat padaoutput analisis menunjukan nilai korelasi $(R)$ sebesar 0.81 menunjukkan hubungan produktivitas penangkapan dengan kondisi oseanografi memiliki kedekatan sebesar $81 \%$. Dan hasil analisis determinasi diperoleh nilai $R^{2}(R$ Square) sebesar 0.66. Hal ini menunjukkan bahwa hubungan kondisi oseanografi denganproduktivitas penangkapan sebesar $66 \%$ sedangkan sisanya 34\% dipengaruhi oleh faktor lain yaitu ketersediaan ikan yang menjadi target penangkapan, serta perubahan kondisi oseanografi dan ketersediaan makanan (Imanda, 2016).

\section{KESIMPULAN}

Produktivitas penangkapan ikan tongkol menggunakan purse seine menunjukkan tertinggi sebesar 14,50 $\mathrm{kg} /$ menit dan terendah $1,87 \mathrm{~kg} /$ menit.

Suhu permukaan laut parameter oseanografi yang signifikan berpengaruh terhadap perubahan produktivitas penangkapan ikan tongkol.

\section{DAFTAR PUSTAKA}

Azlhimsyah R. P., 2016. Selatlektivitas Alat Tangkap Purse Seine Di Pangkalan Pendaratan Ikan (PPI). Jurnal Perikanan Kelautan. Vol. VII (97-102).

Girsang HS. 2008. Studi Penentuan Daerah Penangkapan Ikan Tongkol Melalui Pemetaan Penyebaran Klorofil-a dan Hasil Tangkapan di Palabuhanratu, Jawa Barat [Skripsi]. Bogor: Fakultas Perikanan dan Ilmu Kelautan, Institut Pertanian Bogor. 71 hal.

Idrus I. M. 2016. Produktivitas Daerah Penangkapan Purse Seine Di Perairan Kabupaten Pangkep. [Skripsi]. Makassar. Fakultas Ilmu Kelautan dan Perikanan. Universitas Hasanuddin.

Imanda N. S., 2016. Analisis Faktor-faktor Yang Mempengaruhi Hasil Tangkapan Kapal Mini Purse seine DI Pelabuhan Perikanan Nusantara Pekalongan. Jurnal of Fisheries Resources Utllization Management and Technology. (1) : 145-153. 
Permana, A. 2010. Alat Tangkap Purse

Seine.

Dari Situs

(http://sentikoadipermanapelaut.blogspot.com/2010/10/alattangkap purse-seine.html). Diakses pada tanggal 13 Desember 2017: $19: 48$

Rajab nadia, \& L. Abdul. 2011. Buku Ajar Ichtyologi. Fakultas Perikanan dan Ilmu Kelautan Universitas Haluoleo. Kendari.
Statistik Perikanan Bulukumba. 2014. Potensi Perikanan dan Kelautan. Dari Situs (https://bulukumbakab.go.id/pages/p otensi-prikanan-dan-kelautan). Diakses pada tanggal 8 Februari: 16:21. 